\title{
A produção do conhecimento em ensino de ciências no Oeste Potiguar: Análise das dissertações defendidas em dois programas de pós-graduação em ensino
}

\author{
The production of knowledge in Science teaching in the West of Rio
} Grande do Norte: analysis of dissertations presented in two postgraduate programs in Education

\section{La producción del conocimiento en la enseñanza de ciencias en el Oeste Potiguar: Análisis de las disertaciones defendidas en dos programas de posgrado en enseño}

\author{
Albino Oliveira Nunes (albino.nunes@ifrn.edu.br) \\ Instituto Federal de Educação, Ciência e Tecnologia do Rio Grande do Norte-IFRN \\ Leonardo Alcântara Alves (leonardo.alcantara@ifrn.edu.br) \\ Instituto Federal de Educação, Ciência e Tecnologia do Rio Grande do Norte-IFRN \\ Luciana Medeiros Bertini (luciana.bertini@ifrn.edu.br) \\ Instituto Federal de Educação, Ciência e Tecnologia do Rio Grande do Norte-IFRN \\ Marcelo Nunes Coelho (marcelo.coelho@ifrn.edu.br) \\ Instituto Federal de Educação, Ciência e Tecnologia do Rio Grande do Norte-IFRN
}

Resumo: É notória a expansão e interiorização dos programas de pós-graduação em ensino no Brasil nas últimas décadas. Tendo tal crescimento como ponto de partida, buscamos abordar as discussões feitas em dois programas no interior do RN, Brasil, o PPGE-UERN/Pau dos Ferros e o POSENSINO-UERN/IFRN/UFERSA-Mossoró. Com esse objetivo foi realizada uma pesquisa exploratória de natureza mista (SAMPIERI; COLLADO; LÚCIO, 2014). Compuseram o corpus trinta e nove dissertações e os textos foram codificados no software IRAMUTEQ, versão 0.7 alfa 2, desenvolvido por Ratinaud (2009). Os dados obtidos apontam resultados preliminares que indicam perfis característicos de cada um dos programas analisados. Enquanto o PPGE apresenta pesquisas com predominância no caráter disciplinar e marco teórico para aprendizagem significativa, o POSENSINO apresenta trabalhos mais interdisciplinares com dois grandes marcos de concentração teórica, a aprendizagem significativa e o enfoque CTS. Nota-se ainda que o corpus formado apresenta cinco clusters que podem indicar três grandes categorias. Assim, foi possível inferir que os programas, mesmo "jovens", possuem uma identidade consolidada em termos de marcos teóricos e perfil disciplinar/interdisciplinar, mas também apontam para gargalos na formação dos pósgraduandos, na medida em que estão ausentes algumas perspectivas teóricas importantes para o ensino de ciências em nosso país.

Recebido em: 30/05/2021

Aceite em: 13/08/2021 
Palavras-chave: Ensino; Pós-graduação; IRAMUTEQ.

Abstract: It is notorious the expansion and interiorization of postgraduate programs focusin on Education in Brazil in the last few decades. Considering this growth as a starting point, we aimed to approach the discussions held in two programs located in Rio Grande do Norte, Brazil: PPGE-UERN/Pau dos Ferros, and POSENSINOUERN/IFRN/UFERSA-Mossoró. With this goal, we performed a mixed methods exploratory research (SAMPIERI; COLLADO; LÚCIO, 2014). The corpus was composed of thirty nine dissertations and the texts were codified in the software IRAMUTEQ, version 0.7 alpha 2, developed by Ratinaud (2009). the data obtained point to preliminary results that indicate the characteristic profiles of each of the programs analyzed. While PPGE shows works with a disciplinary profile as well as theoretical breakthrough for significant learning, POSENSINO shows works that are more interdisciplinary, with two major theoretical focus breakthroughs, significant learning and STS approach. It is also noticeable that the assembled corpus shows five clusters that may indicate three major categories. Thus, it was possible to infer that the programs, even though fairly "young", possess a consolidated identity in terms of theoretical breakthroughs and disciplinary/interdisciplinary profile, but also point to bottlenecks in the formation of graduates, in such that it leaves a gap for other important theoretical perspectives for the teaching of Sciences in our country.

Keywords: Teaching; Postgraduate; IRAMUTEQ.

Resumen: Es notoria la expansión e interiorización de los programas de posgrado en enseño en el Brasil en las últimas décadas. Teniendo tal conocimiento como puento de partida, buscamos abordar las discusiones hechas en dos programas en el interior del RN, Brasil, el PPGE-UERN/Pau dos Ferros y el POSENSINO-UERN/UFERSAMossoró. Con ese objetivo fue realizada una pesquisa exploratoria de naturaleza paritaria (SAMPIERI; COLLADO; LÚCIO, 2014). Compusieron el corpus treinta y nueve disertaciones, y los textos fueron codificados en el software IRAMUTEQ, versión 0.7 alfa 2, desarrollado por Ratinaud (2009). Los dados obtenidos apuntan resultados iniciales que indican perfiles característicos de cada un de los programas analizados. Mientras el PPGE presenta pesquisas con predominio en el carácter disciplinar y marco teórico para aprendizaje significativa, el POSENSINO presenta trabajos más interdisciplinares con dos grandes marcos de concentración teórica, el aprendizaje significativo y el abordaje CTS. Percibe-se aunque que el corpus formado presenta cinco clusters que pueden indicar tres grandes categorías. Así, fue posible deducir que los programas, mismo "jóvenes", poseen una identidad consolidada en termos de marcas teóricas y perfiles disciplinar/interdisciplinar, pero también apuntan para gollete en la formación de los estudiantes de posgrado, en la medida en que están ausentes otras perspectivas teóricas importantes para en enseño de ciencias en nuestro país.

Palabras-clave: Enseño; Posgrado; IRAMUTEQ.

\section{INTRODUÇÃO}

Recebido em: 30/05/2021

Aceite em: 13/08/2021 
Que as ciências figuram entre as mais impressionantes construções da humanidade, não se discute. Sua relevância ao longo dos séculos fez com que se tornasse o que hoje podemos chamar de indispensável. Foi em virtude desse caráter impreterível das ciências para a sociedade, que surgiram, já há mais ou menos 200 anos (YAGER, 1996), os primeiros currículos escolares de ciências. Na época, a física se consolidava como uma atividade prática e social (AIKENHEAD, 1994), além de uma atividade intelectual. A inserção, o amadurecimento, as reformas, a discussão dos currículos de ciências nos ambientes formais de ensino e aprendizagem foi o fio condutor da pesquisa em ensino de ciências.

As primeiras investigações nesse campo começam a ganhar contornos, ainda pouco nítidos, já na segunda década do século XX, momento em que ocorre a edição do primeiro número da revista Science Education (1916), "um marco para a constituição do campo de pesquisa em ensino de ciências e matemática" (GENOVESE et al., 2016). No entanto, é seguro afirmar que o campo de pesquisa em ensino de ciências e matemática se define de forma mais clara a partir da década de 1950 com a criação dos Projetos Curriculares Nacionais nas áreas de Ciências da Natureza e Matemática (PSSC, IPS, BSCS, CHEM'S e $\mathrm{CBA}^{1}$ ).

No Brasil, a área começa a se delinear já na década de 1930. Mas só começa a ganhar impulso mesmo nas décadas de $1960 / 70^{2}$ e boa parte das atividades desenvolvidas por seus membros centra-se na tradução e adaptação dos já referidos Projetos Curriculares o que, consequentemente, acaba levando à criação dos outros projetos adequados à realidade brasileira $\left(\mathrm{PEF}, \mathrm{FAI}, \mathrm{PBEF}\right.$ e $\left.\mathrm{GREF}^{3}\right)$. É nesse cenário de crescente interesse que se situa historicamente o primeiro Simpósio Nacional de Ensino de Física (SNEF), realizado em 1970 no Instituto de Física da USP. A vanguarda da área de ensino de física decorre, principalmente, do fato de que a maioria dos pesquisadores envolvidos com investigações em ensino de ciências, naquele

\footnotetext{
${ }^{1}$ PSSC - Physical Science Study Committee, IPS - Introductory Physical Sciences, BSCS - Biological Sciences Curriculum Study, CHEM'S - Chemical Education Materials Study e CBA - Chemical Bond Approach.

${ }^{2}$ A pesquisa desenvolvida nesse período de gênese, pode ser caracterizada em três fases: i) até 1955 predominam estudos de natureza psicopedagógica; ii) 1956 até 1964 estudos com enfoque sociológico; e iii) 1964 a 1970 estudos de natureza econômica (TEIXEIRA, 2008)

${ }^{3}$ PEF - Projeto de Ensino de Física, FAI - Física Auto-Instrutivo, PBEF - Projeto Brasileiro para o Ensino de Física e GREF - Grupo de Re-elaboração do Ensino de Física.
}

Recebido em: 30/05/2021

Aceite em: 13/08/2021 
momento, eram físicos. Entretanto, não tarda muito, a comunidade de pesquisadores começa a diversificar e, em 1980, acontece o primeiro Encontro de Debates sobre o Ensino de Química (EDEQ) no Rio Grande do Sul.

No último meio século, o crescimento da pesquisa e da produção de conhecimento relacionado ao Ensino de Ciências tem sido notável, uma consequência de demandas sociais e de ações visando respondê-las. Destaque para a criação da Área de Ensino de Ciências e Matemática, pela Coordenação de Aperfeiçoamento de Pessoal de Nível Superior (CAPES), em 2000, o que refletiu direta e positivamente no aumento do número de Programas de Pós-Graduação voltados para as pesquisas no Ensino de Ciência e Matemática. Contava-se, no momento de criação da área 46 (Ensino de Ciências e Matemática) com sete programas de pós-graduação. Em 2008, a CAPES resolveu extinguir a área de Ensino de Ciências e Matemática e criar a área de Ensino. Neste momento, já contava com 29 mestrados acadêmicos, 19 doutorados e 30 mestrados profissionais (CAPES, 2019). Em 2011, os números já registravam 20 doutorados, 32 mestrados acadêmicos e 34 mestrados profissionais (TEIXEIRA, 2008). No último documento da área 46, verifica-se 39 doutorados, 80 mestrados acadêmicos, 95 mestrados profissionais e 4 de doutorados profissionais, totalizando 218 cursos (CAPES, 2019).

Ainda sobre esse crescimento nos cursos stricto sensu de ensino, um aspecto importante que se deve apontar ao avaliar a área de pesquisa se refere à sua regionalização, em que, segundo o seu Documento de Área (CAPES, 2019), é nítida uma predominância dos cursos ofertados nas regiões Sudeste (78) e Sul (60), seguidos do Nordeste (36), Centro-Oeste (23) e Norte (21). Tal desequilíbrio é comum entre outras áreas de conhecimento e é consequência da própria história da educação superior no Brasil que, apesar de ter surgimento no Brasil Colônia, nos cursos de Filosofia e Teologia que eram ministrados pelos jesuítas, teve seu foco com a criação da primeira Universidade brasileira, em 1920, no Rio de Janeiro, e da Universidade de São Paulo, em 1934 (GOMES; MACHADO-TAYLOR; SARAIVA, 2018), o que reflete ainda hoje nos cursos de graduação e pós-graduação do país.

Direcionando nosso olhar para os temas presentes nas investigações sobre ensino de ciências, bem como os referenciais teóricos e as metodologias empregadas nessas 
investigações, podemos observar que tais aspectos se encontram em constante evolução, sempre em busca de se adequar às realidades sociais e culturais em que o processo de ensino e aprendizagem se insere. Cachapuz et al. (2011) refletem sobre as diversas linhas de pesquisa encontradas em publicações que podem auxiliar no direcionamento de quais principais temáticas desenvolvidas, com destaque para: a) concepções alternativas; b) resolução de problemas; c) práticas de laboratório e práticas de campo; d) currículo; e) materiais didáticos; f) relações ciência/tecnologia/sociedade; g) linguagem e comunicação; h) avaliação; i) formação de professores; j) concepções epistemológicas dos docentes; 1) história da ciência e m) questões axiológicas. Os autores apontam ainda que as três primeiras temáticas já cobrem as ditas "componentes clássicas" para o ensino de ciências, ao analisar a teoria, os problemas e as práticas. Entretanto, nos cabe apontar que diversas outras linhas de discussão são essenciais para darmos conta da complexidade envolvida no desenvolvimento dessa área de conhecimento, dita emergente, visto que ensinar ciências tem um papel social importante por possibilitar ao estudante entender melhor seu contexto e os fenômenos relacionados a ele (FERREIRA; MÜNCHEN, 2020).

Dessa forma, é mister a constante preocupação em conhecer o que se tem produzido na pós-graduação brasileira e, tendo em vista os apontamentos realizados, nesse texto buscamos entender como se encontram os processos de produção de conhecimento na pós-graduação em ensino em cursos ofertados fora de grandes centros urbanos, mais especificamente no oeste do Rio Grande do Norte, Nordeste, Brasil. Para isto, buscou-se trabalhar com programas de origem mais recente, ainda em processos de consolidação de suas atividades, sendo analisados os trabalhos oriundos de dissertações do POSENSINO (UERN/UFERSA/IFRN - Mossoró) e do PPGE (UERN - Pau dos Ferros).

Estudos como estes se justificam na medida em que permitem, não só conhecer o que se produziu, mas também decidir novos rumos a seguir e lacunas ainda não contempladas, "além de socializarem, compatibilizarem, caracterizarem e integrarem os conhecimentos gerados pelas pesquisas, os tornando, desta forma, agentes efetivos de mudança na educação em Ciências no país, tanto regional quanto nacionalmente" (SILVA; AMARAL, 2015). 


\title{
2. PERCURSO METODOLÓGICO
}

O estudo aqui proposto caracteriza-se como de desenho com método misto assim como descrito por Pérez (2011), no qual não há uma predominância de uma abordagem sobre a outra, mas uma associação simétrica. Ao abordar os desenhos com métodos mistos a autora os classifica como (Pérez, 2011, p. 20):

\begin{abstract}
Tipos de diseño con método mixto: Para la clasificación de diseños con método mixto, es decir, aquellos que combinan metodologías cuantitativas y cualitativas, los autores señalados proponen los siguientes tipos: Tipo I: Investigación confirmatoria, con datos cualitativos y análisis estadístico. Tipo II: Investigación confirmatoria, con datos cualitativos y análisis cualitativo. Tipo III: Investigación exploratoria, con datos cuantitativos y análisis estadísticos. Tipo IV: Investigación exploratoria, con datos cualitativos y análisis estadístico. Tipo V: Investigación confirmatoria, con datos cuantitativos y análisis cualitativo. Tipo VI: Investigación exploratoria, con datos cuantitativos y análisis cualitativo. (grifo nosso).
\end{abstract}

Assim, o artigo que apresentamos se classifica como do tipo VI, investigação exploratória, com dados quantitativos e análise qualitativa. Outro aspecto para caracterizar o estudo como misto foi a natureza intersubjetiva do objeto estudado.

Para a formação dos corpora de análise foi feita a busca direta pelas dissertações das linhas de Ensino de ciências exatas e naturais (PPGE - UERN/Pau dos Ferros) e Ensino de ciências naturais e tecnologia (POSENSINO - UERN/IFRN/UFERSAMossoró) no site dos referidos programas. A escolha por tais programas deve-se ao fato de serem programas novos (PPGE-2014 e POSENSINO-2016) e, portanto, ainda em processo de consolidação. Para a composição dos dois corpora foram consideradas para a análise apenas as dissertações que versassem sobre o ensino de química, física, biologia ou ciências em geral, sendo excluídas as dissertações de ensino de tecnologia, educação ambiental e educação matemática/estatística. Ao final compuseram o corpus trinta e nove dissertações sendo vinte e três do PPGE e dezesseis do POSENSINO.

Em seguida, os textos dos resumos das dissertações selecionadas foram codificados e trabalhados no software Interface de $\mathrm{R}$ pour les Analyses Multidimensionnelles de Textes et de Questionnaires (IRAMUTEQ), versão 0.7 alfa 2 , desenvolvido por Rautinaud (2009).

É preciso esclarecer que quanto ao método, usamos predominantemente a análise lexicométrica que tem uma tradição francesa que remonta os anos 60/70, não se Recebido em: 30/05/2021

Aceite em: 13/08/2021 
confundindo com a análise de conteúdo ou de discurso clássicas. Há que se ressaltar que no uso da análise lexicométrica aqui utilizada outros elementos foram incluídos como a análise de segmentos de texto representativos dos corpora.

Aqui temos que justificar a utilização do software em virtude do grande volume de dados textuais, a análise e a obtenção de uma síntese tornam-se dificultadas. Assim, optou-se pela adoção do programa informático na organização dos dados. No entanto, compreende-se no âmbito desse estudo, assim como em outros pesquisadores (RAMOS; LIMA; AMARAL-ROSA, 2018; CAMARGO; JUSTO, 2013; SOUSA; SILVA, 2021), que o software não retira do analista o seu papel de interpretação do material, apenas facilita tal processo. Nos apoiamos, também, nos estudos de Souza et al. (2018) e Souza, Nunes e Oliveira (2020) para adotar uma interpretação predominantemente qualitativa sobre os dados quantitativos apresentados pelo software, reafirmando a natureza da pesquisa já apontada no início desta seção.

\section{RESULTADOS E DISCUSSÃO}

Para melhor entendimento dos dados separou-se os dois corpora, sendo analisado inicialmente o Programa de Pós-Graduação em Ensino (POSENSINO), associação ampla entre a Universidade do Estado do Rio Grande do Norte, Universidade Federal Rural do Semi-Árido e o Instituto Federal de Educação, Ciência e Tecnologia do Rio Grande do Norte. A seguir uma breve descrição do programa e os resultados obtidos da análise das dissertações.

- Posensino

Sendo um programa em consolidação, iniciando suas atividades em 2016, o POSENSINO apresenta-se situado na cidade de Mossoró, cidade do interior do Rio Grande do Norte. Segundo o site do próprio programa:

O Programa de Pós-Graduação stricto sensu em Ensino (POSENSINO), associação UERN, UFERSA e IFRN, assume como compromisso o desenvolvimento da pesquisa teórico-prática nos diversos níveis, modalidades e áreas de ensino, dando ênfase no processo ensinoaprendizagem na escola pública. Pretende ainda possibilitar uma visão integradora e interdisciplinar da ação docente, capacitando para a docência e para a pesquisa na área de Ensino nos múltiplos espaços da escola pública (POSENSINO, 2021). 
Para atingir tal objetivo expresso o programa conta com três linhas de pesquisa que, apesar de dialogarem entre si e com a área de concentração possuem especificidades. São Elas: Linha de Pesquisa 1 - Ensino de Ciências Humanas e Sociais; Linha de Pesquisa 2 - Ensino de Línguas e Artes; Linha de Pesquisa 3- Ensino de Ciências Naturais e Tecnologias.

A linha três, foco da análise nesse artigo descreve assim suas intencionalidades:

\begin{abstract}
Busca desenvolver investigações no âmbito do ensino-aprendizagem das ciências naturais, matemática e tecnologias em uma perspectiva interdisciplinar. Com foco na investigação sobre materiais didáticos, tecnologias educacionais e metodologias de ensino no âmbito de disciplinas do ensino básico, da formação técnica e do ensino superior. Assim, visa contribuir com a efetiva melhoria na qualidade do ensino-aprendizagem no contexto da escola pública, nos seus diversos níveis, auxiliando na superação dos problemas vivenciados nessa esfera (POSENSINO, 2021).
\end{abstract}

Atualmente a linha conta com seis pesquisadores-orientadores, dos quais três têm formação em química, um com formação em física e dois com formação em matemática, o que reflete diretamente na amostra e resultados encontrados.

Partindo para as análises e achados da pesquisa, temos inicialmente a nuvem de palavras formada com a frequência dos lemas encontrados nos resumos do POSENSINO (Figura 1). Como se pode notar claramente o foco de tais dissertações está condizente com a área do programa, "Ensino", e contempla em grande destaque a "aprendizagem", o que pode nos direcionar a duas inferências a serem testadas. A de que o termo aparece em decorrência da compreensão de que não se pode separar ensino e aprendizagem ou de que muitos trabalhos versam sobre a aprendizagem significativa, uma vez que o lema "significativo" aparece em destaque no corpus. Outros lemas que merecem destaque no corpus são: aula, aluno, científico, ciência, trabalho, pesquisa. Notamos aqui que aparentemente não há um destaque grande para os conteúdos disciplinares (química, física e biologia) o que pode ser em decorrência da configuração do curso que prioriza abordagens interdisciplinares. Há sim, uma presença de palavras que indicam a área de ciências. 
Figura 1 - Nuvem de palavras - POSENSINO

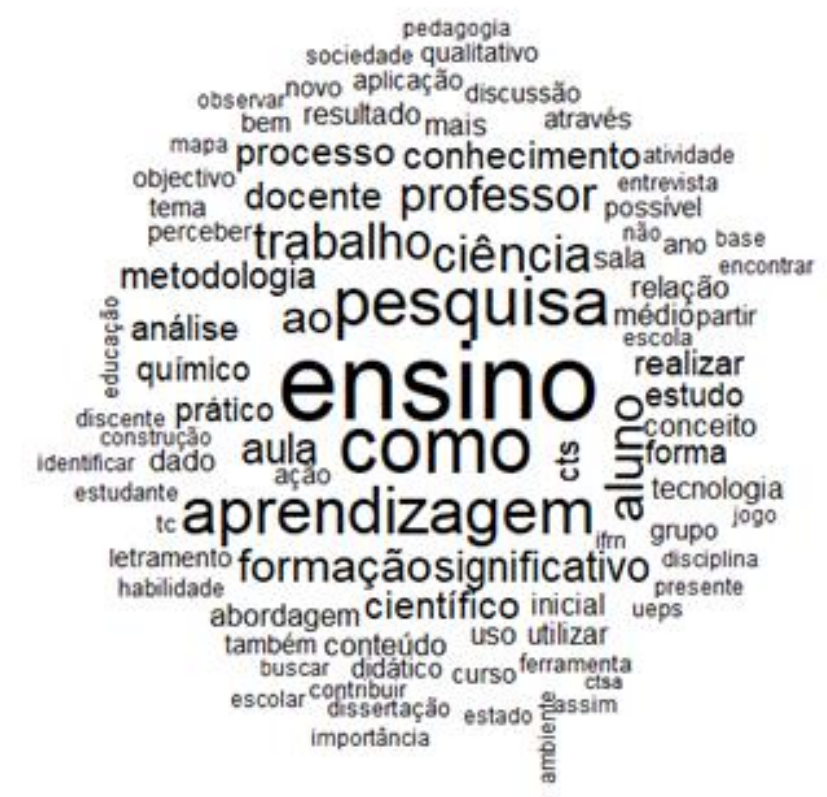

Fonte: Aos autores (2021), organizado com base no software IRAMUTEQ

Como segundo dado a ser analisado, trazemos a árvore máxima do grafo de similitude, conforme apresentado na Figura 2, a seguir. Essa análise proporciona uma visualização mais precisa sobre o significado da ocorrência das palavras no corpus por indicar a coocorrência dos lemas e a força de relação entre eles. Vemos que a relação mais forte, expressa pela espessura da ligação entre as palavras se dá entre ensino e aprendizagem, corroborando a primeira inferência da nuvem de palavras de que esses lemas estão associados nos trabalhos analisados. Uma relação de menor intensidade também ocorre entre as palavras aprendizagem e significativo o que denota que parte do material se volta a essa perspectiva teórico-metodológica. Outra relação presente que merece destaque é a relação ensino-pesquisa, o que pode ser uma clara sinalização de que há uma preocupação com os fundamentos da pesquisa em ensino na linha do programa.

Recebido em: 30/05/2021

Aceite em: 13/08/2021 
Figura 2 - Grafo de Similitude - POSENSINO

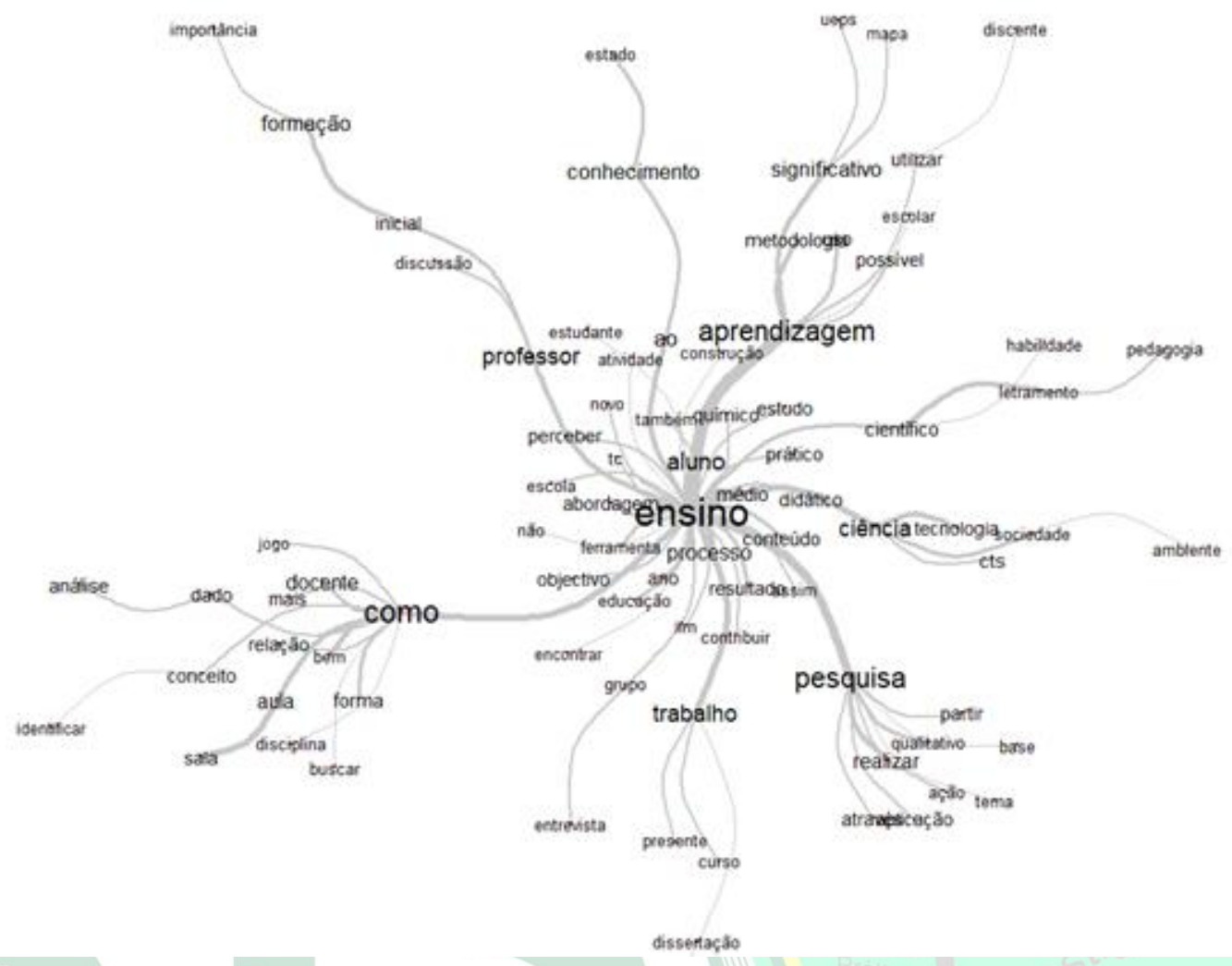

Fonte: Aos autores (2021), organizado com base no software IRAMUTEQ

Uma vez analisada a árvore máxima, buscamos compreender a classificação hierárquica descendente (CHD) do corpus e inferir confluências entre as análises. $\mathrm{O}$ primeiro destaque é que a palavra Ensino não aparece entre as classificadas na figura 3. O que pode parecer estranho à primeira vista, uma vez que o lema tem 99 ocorrências no corpus, pode ser explicado quando se analisa os segmentos de texto por categoria e percebe-se que este aparece nos segmentos de várias classes, não podendo assim estar em uma única.

A inferência das classes/categorias ganha maior significado ao analisarmos o dendrograma na Figura 3. Percebe-se que a classe 1 versa sobre o foco teórico de várias dissertações - a aprendizagem significativa. A classe dois trata principalmente sobre a análise documental e de literatura. A terceira sobre o foco temático de uma única dissertação o Teatro científico (TC), a quarta especificamente sobre questões de caracterização dos percursos metodológicos e a quinta sobre a fundamentação da educação em ciências e tecnologia.

Figura 3 - CHD - POSENSINO

Recebido em: 30/05/2021

Aceite em: 13/08/2021 


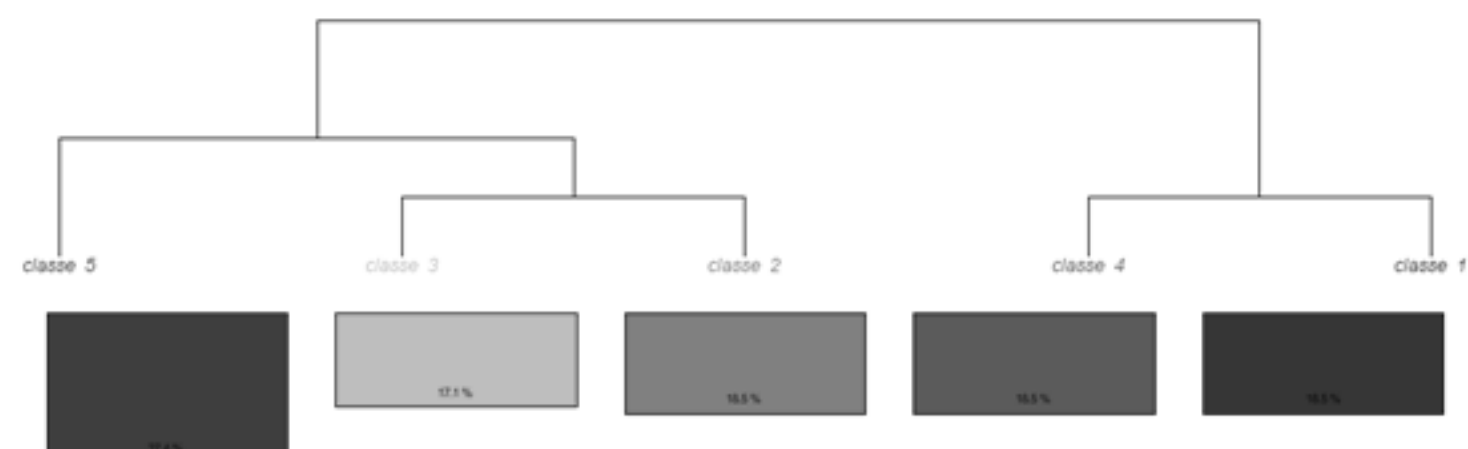

\begin{tabular}{|c|c|c|}
\hline educação & conhecer & literatura \\
\hline não & tc & curso \\
\hline ciência & nivel & tema \\
\hline contribuir & mossoró & importância \\
\hline possivel & cidade & $\mathrm{ppc}$ \\
\hline tecnologia & ao & abordar \\
\hline questão & público & infantil \\
\hline sociedade & atuar & tese \\
\hline ecossistema & grupo & periódico \\
\hline vida & ano & artigo \\
\hline $\begin{array}{l}\text { social } \\
\text { processo }\end{array}$ & atividade & livro \\
\hline escolar & mesmo & $\begin{array}{l}\text { formaçáo } \\
\text { análise }\end{array}$ \\
\hline $\begin{array}{l}\text { informaçào } \\
\text { aprender }\end{array}$ & desenvolver & discussão \\
\hline & $\begin{array}{l}\text { aspecto } \\
\text { fundamental }\end{array}$ & identificar \\
\hline sempre & $\begin{array}{l}\text { Tundamental } \\
\text { escola }\end{array}$ & conceito \\
\hline $\begin{array}{l}\text { cidadäo } \\
\text { causa }\end{array}$ & publicação & $\begin{array}{l}\text { dissertaçao } \\
\text { estado }\end{array}$ \\
\hline $\begin{array}{l}\text { causa } \\
\text { habilidade }\end{array}$ & interdisciplinar & $\begin{array}{l}\text { gás } \\
\text { gáo }\end{array}$ \\
\hline $\begin{array}{l}\text { habilidade } \\
\text { estudante }\end{array}$ & final & \\
\hline $\begin{array}{l}\text { estudante } \\
\text { necessidade }\end{array}$ & busca & $\begin{array}{l}\text { perspectiva } \\
\text { periodo }\end{array}$ \\
\hline $\begin{array}{l}\text { necessidade } \\
\text { continuar }\end{array}$ & tradicional & estudo \\
\hline $\begin{array}{l}\text { continuar } \\
\text { grande }\end{array}$ & relatar & cts \\
\hline biente & tato & alternativo \\
\hline qualidade & botâniça & pedagogia \\
\hline cientifico & & núme \\
\hline & herimente & \\
\hline
\end{tabular}

\begin{tabular}{|c|c|}
\hline qualitativo & aprendizager \\
\hline quantitativo & sentido \\
\hline pesquisa & utilizacão \\
\hline escala & significativo \\
\hline likert & objeto \\
\hline série & atrativo \\
\hline questionário & aula \\
\hline predeterminado & metodologia \\
\hline constituir & teoria \\
\hline mapa & auxiliar \\
\hline médio & estequiometria \\
\hline conceitual & resultado \\
\hline $\begin{array}{l}\text { fundamentar } \\
\text { diaital }\end{array}$ & construção \\
\hline $\begin{array}{l}\text { digital } \\
\text { teste }\end{array}$ & uso \\
\hline $\begin{array}{l}\text { teste } \\
\text { jogo }\end{array}$ & sala \\
\hline $\begin{array}{l}\text { jogo } \\
\text { aplicação }\end{array}$ & assim \\
\hline $\begin{array}{l}\text { aplicação } \\
\text { base }\end{array}$ & ueps \\
\hline & alternativa \\
\hline $\begin{array}{l}\text { potencialmente } \\
\text { analisado }\end{array}$ & processo \\
\hline trabalho & vez \\
\hline teórico & como \\
\hline forma & mais \\
\hline verificar & relevância \\
\hline utilizar & tornar \\
\hline unidade & aluno \\
\hline metodologico & surgir \\
\hline bibliograffico & promover \\
\hline 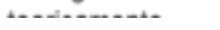 & instrumento \\
\hline
\end{tabular}

Fonte: Aos autores (2021), organizado com base no software IRAMUTEQ

A seguir apresentamos um quadro síntese com as classes, categorias e lemas com $\mathrm{p}<0,005$.

Quadro 1 - Categorias e Lemas - POSENSINO

\begin{tabular}{|c|c|c|}
\hline Classe & Categoria & Lemas (p <0,005) \\
\hline Classe 1 & Aprendizagem significativa & $\begin{array}{c}\text { Aprendizagem, sentindo, } \\
\text { construção, significativo, } \\
\text { objeto, atrativo, aula, } \\
\text { metodologia, teoria, auxiliar, } \\
\text { estequiometria e resultado. }\end{array}$ \\
\hline Classe 2 & Análise de documentos & $\begin{array}{c}\text { Literatura, curso, tema, } \\
\text { importância, ppc, abordar, } \\
\text { infantil, tese, periódico, } \\
\text { artigo, livro, formação, }\end{array}$ \\
\hline
\end{tabular}

Recebido em: 30/05/2021

Aceite em: 13/08/2021 


\begin{tabular}{|c|c|c|}
\hline & & análise e discussão. \\
\hline Classe 3 & Teatro científico & $\begin{array}{c}\text { Conhecer, TC, nível, } \\
\text { Mossoró, cidade, público, } \\
\text { atuar, grupo, ano e atividade. }\end{array}$ \\
\hline Classe 4 & Metodologias & $\begin{array}{l}\text { Qualitativo, quantitativo, } \\
\text { pesquisa, escala, likert, série, } \\
\text { questionário, predeterminado, } \\
\text { constituir, mapa, médio, } \\
\text { conceitual, fundamentar, } \\
\text { digital e teste. }\end{array}$ \\
\hline Classe 5 & $\begin{array}{c}\text { Educação em Ciências para } \\
\text { cidadania }\end{array}$ & $\begin{array}{l}\text { Educação, não, ciência, } \\
\text { contribuir, possível, } \\
\text { tecnologia, questão, } \\
\text { sociedade, ecossistema, vida, } \\
\text { social, processo, escolar, } \\
\text { informação, aprender, } \\
\text { socioambientais, sempre, } \\
\text { cidadão e causa. }\end{array}$ \\
\hline
\end{tabular}

Fonte: Aos autores (2021)

Notamos dessas categorias emergentes, que: 1) as classes 2 e 3 não se constituem em uma única categoria de análise por versarem sobre temas distintos; 2) Percebe-se uma ocorrência de forte vinculação entre a Educação em ciências para a cidadania e questões sociais na classe 5; 3) A aprendizagem significativa é um importante referencial para as dissertações produzidas no programa e 4) Há certo equilíbrio entre a abordagem qualitativa e quantitativa.

\section{- PPGE}

Sobre o PPGE o site do próprio programa informa que:

O Programa de Pós-Graduação em Ensino (PPGE), criado em $2013^{4}$, oferece o Curso de Mestrado Acadêmico em Ensino (CMAE) [...] O PPGE atende egressos de cursos de licenciatura e, também, profissionais que atuam nos diferentes níveis e modalidades da educação básica e da educação superior (bacharéis, tecnólogos ou licenciados), com interesse nos processos de ensino e aprendizagem na educação básica, sobretudo nas áreas de ensino de ciências exatas e naturais, de ciências humanas e sociais e no ensino de línguas. [...] $\mathrm{O}$ egresso do PPGE deve ter um perfil profissional que o possibilita compreender o processo ensino-aprendizagem e nele intervir, numa efetiva interação e articulação com as áreas do conhecimento e diferentes níveis e modalidades da Educação Básica. Na perspectiva de intervir nos estudos e nas práticas educativas, o egresso o fará mediado por novos referenciais teóricos e metodológicos voltados para o desenvolvimento de habilidades criativas e inovadoras do processo didático-pedagógico e para sua aplicação nas áreas das ciências, das humanidades e das linguagens (PPGE, 2021).

${ }^{4}$ Curso autorizado em 2013, sendo a primeira turma de 2014.

Recebido em: 30/05/2021

Aceite em: 13/08/2021 
Assim como o POSENSINO o PPGE também apresenta três linhas de pesquisa:

Linha 1 - Ensino de Ciências Exatas e Naturais; Linha 2 - Ensino de Ciências Humanas

e Sociais; Linha 3 - Ensino de Línguas. Sobre a primeira linha, o site do programa informa a intencionalidade:

\begin{abstract}
Articula pesquisas e produtos educacionais envolvendo a problematização da pesquisa científica e metodologias que contribuam com a área do ensino de ciências exatas e naturais. Focaliza estratégias voltadas para resolução de situações problemas, aprendizagem significativa, construção de mapas conceituais, modelos de mudanças conceituais, priorizando as habilidades comunicativas de refletir, compreender, classificar, argumentar, descrever, justificar, dentre outras, com base nos conceitos e princípios da aprendizagem de ciências e na compreensão e explicação dos problemas de recursos naturais e ambientais da região do semiárido nordestino. Objetiva estimular a vivência de investigação dos problemas de ensino e aprendizagem na área em foco, assim como a reflexão das atividades em sala de aula, por meio de atitudes de curiosidade, desejo de experimentação, dúvidas e confronto de resultados (PPGE, 2021).
\end{abstract}

A linha em questão apresenta sete pesquisadores, com maior diversidade de formações em relação ao programa anteriormente trabalhado. Sendo uma enfermeira, um Graduado em Tecnologia de Alimentos, três físicos, uma química e uma pedagoga.

No tocante aos dados apresentados pelo Iramuteq, temos que a nuvem de palavra (Figura 4) traz elementos parecidos com a nuvem de palavras do outro programa analisado. Lemas como "ensino", “aprendizagem”, já presentes no outro corpus aparecem. Cabe aqui um destaque o lema “químico" que aparece quase tão destacado como ensino, indicando que grande parte das dissertações tratam sobre conhecimentos químicos. Faz-se a ressalva de que apesar de ter apenas uma orientadora com formação em química, diferente do POSENSINO que tem três, as propostas parecem ser mais disciplinares nesse programa e mais interdisciplinares no primeiro. 
Figura 4 - Nuvem de palavras PPGE

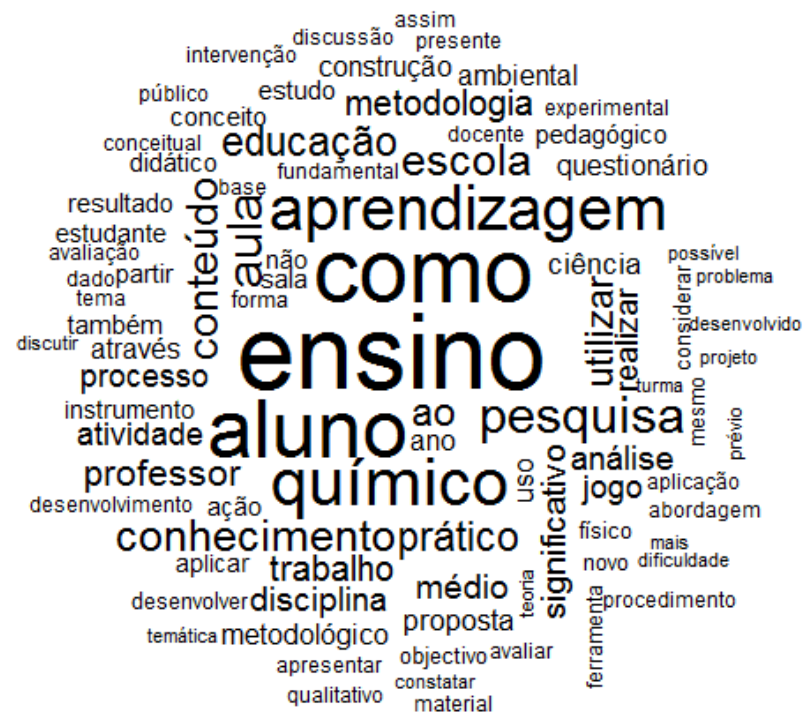

Fonte: Aos autores (2021), organizado com base no software IRAMUTEQ

Seguindo o mesmo raciocínio do programa anterior apresentamos o grafo de similitude (árvore máxima) do PPGE (Figura 5).

Figura 5 - Grafo de Similitude - PPGE

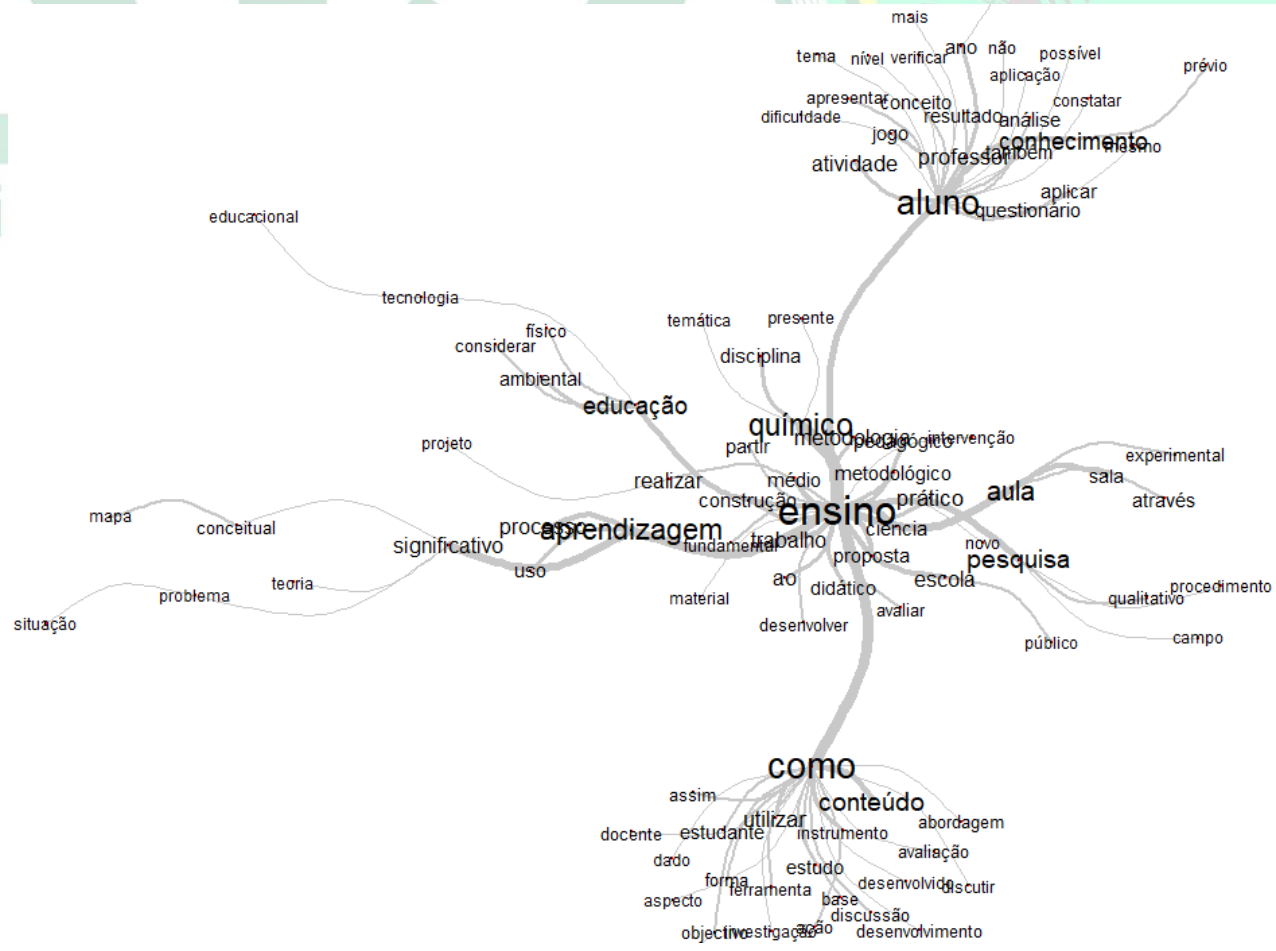

Fonte: Aos autores (2021), organizado com base no software IRAMUTEQ

Recebido em: 30/05/2021

Aceite em: 13/08/2021 
O grafo de similitude nesse caso reforça as primeiras impressões já elencadas sobre a nuvem de palavras. Há grande similaridade sobre as amostras: a) O ensino é central nos textos; b) a ênfase na aprendizagem está relacionada em muitos casos à teoria da aprendizagem significativa; c) o foco maior é o aluno, e não a formação de professores; Ressaltando-se como diferença a presença do ensino de química como indicador de propostas mais voltadas à disciplinaridade.

Por fim, como análises associadas temos a CHD (Figura 6).

Figura 6 - CHD - PPGE

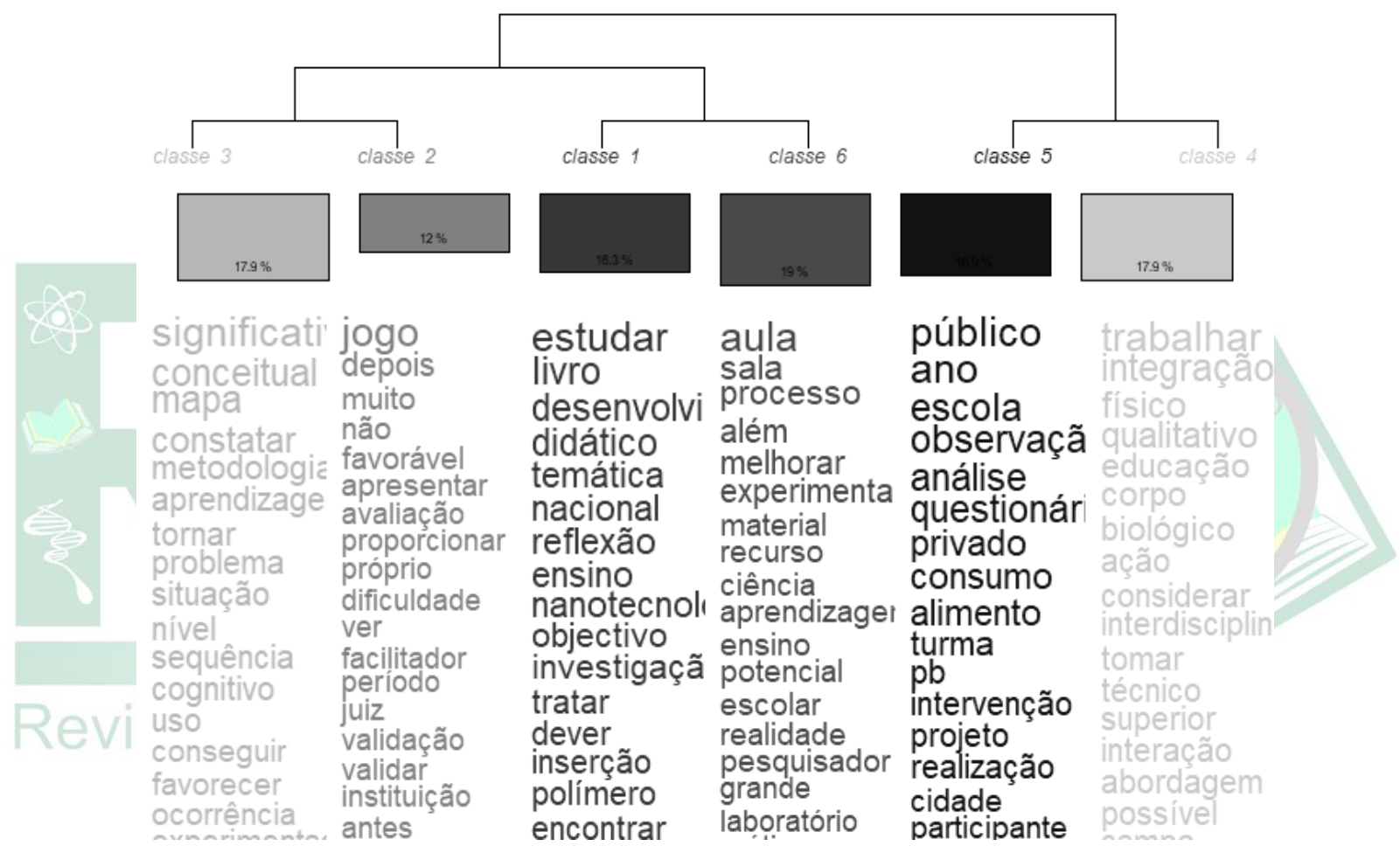

Fonte: Aos autores (2021), organizado com base no software IRAMUTEQ

Como se pode inferir no quadro 2, o corpus forma quatro categorias que são apresentadas a seguir:

Quadro 2 - Categorias e Lemas - PPGE

\begin{tabular}{|c|c|c|}
\hline Classe & Categoria & Lemas (p <0,005) \\
\hline Classe 1 & $\begin{array}{c}\text { Estudar, livro, } \\
\text { Ensino-aprendizagem da } \\
\text { ciência }\end{array}$ & $\begin{array}{c}\text { desenvolvimento, didático, } \\
\text { temática, nacional, reflexão } \\
\text { ensino, nanotecnologia }\end{array}$ \\
\hline Classe 2 & $\begin{array}{c}\text { Avaliação de recursos } \\
\text { didáticos }\end{array}$ & $\begin{array}{c}\text { Jogo, depois, muito, não, } \\
\text { favorável, apresentar, }\end{array}$ \\
\hline
\end{tabular}

Recebido em: 30/05/2021

Aceite em: 13/08/2021 


\begin{tabular}{|c|c|c|}
\hline & & $\begin{array}{l}\text { avaliação, proporcionar, } \\
\text { próprio }\end{array}$ \\
\hline Classe 3 & $\begin{array}{l}\text { Avaliação de recursos } \\
\text { didáticos }\end{array}$ & $\begin{array}{l}\text { Significativo, conceitual, } \\
\text { mapa, constatar, } \\
\text { metodologia, } \\
\text { aprendizagem, tornar, } \\
\text { problema, situação, nível, } \\
\text { sequência, cognitivo, uso }\end{array}$ \\
\hline Classe 4 & $\begin{array}{c}\text { Conteúdos de ciências e } \\
\text { avaliação }\end{array}$ & $\begin{array}{l}\text { Trabalhar, integração, } \\
\text { físico, qualitativo, } \\
\text { educação, corpo, biológico, } \\
\text { ação }\end{array}$ \\
\hline Classe 5 & Metodologia & $\begin{array}{c}\text { Público, ano, escola, } \\
\text { observação, análise, } \\
\text { questionário, privado, } \\
\text { consumo, alimento, turma }\end{array}$ \\
\hline Classe 6 & $\begin{array}{c}\text { Ensino - aprendizagem da } \\
\text { ciência }\end{array}$ & $\begin{array}{l}\text { Aula, sala, processo, além, } \\
\text { melhorar, experimental, } \\
\text { material, recurso, ciência }\end{array}$ \\
\hline
\end{tabular}

Fonte: Aos autores (2021)

Ressaltamos que assim como no corpus anterior emerge uma classe metodológica muito clara (Classe 5 - Metodologia), na qual nota-se a observação e o questionário como técnicas principais, sendo e o lócus da pesquisa dividido entre a escola pública e a privada.

Há que se destacar que a classe 4 (Conteúdos de ciências e avaliação) reafirma o caráter central dos conteúdos (física e biologia) no contexto do programa o que diferencia de uma abordagem mais interdisciplinar do POSENSINO. Sobre as classes 2 e 3, agrupadas em uma única categoria, pode-se inferir que tratam respectivamente do uso de jogos e mapas conceituais bem como a avaliação desses recursos didáticos. Por fim, temos a categoria Ensino-aprendizagem na qual foram agrupadas as classes 1 e 6 onde temos questões gerais de didática que envolvem o ensino-aprendizagem de ciências.

\section{CONSIDERAÇÕES FINAIS}

Ao analisar os dados nas seções anteriores chega-se a algumas conclusões: a) Os programas de Pós-Graduação em Ensino da região do oeste potiguar têm seus próprios perfis na produção do conhecimento. O PPGE apresenta um perfil de dissertações voltadas ao ensino de química, física e biologia (ainda que o primeiro seja Recebido em: 30/05/2021 
predominante). O POSENSINO apresenta trabalhos mais interdisciplinares, principalmente no âmbito da abordagem Ciência, Tecnologia e Sociedade. b) Outro destaque que diferencia os dois programas é a presença marcante do enfoque CTS em várias dissertações do programa situado em Mossoró. Há, no entanto, semelhanças marcantes: i) Ambos os programas se dedicam ao ensino-aprendizagem dos conhecimentos de ciências voltadas ao estudante; ii) É forte a presença da teoria da aprendizagem significativa em ambos os programas, iii) Apesar de não serem foco mensurável ao analisarmos o todo dos textos, quando buscamos uma análise individual das produções fica claro que os trabalhos conversam diretamente com as linhas de pesquisa apontadas por Cachapuz et al. (2011), ao discutirem os temas: materiais didáticos, práticas de laboratório, resolução de problemas, formação de professores, entre outros fortemente importantes para o desenvolvimento da pesquisa na área de ensino das ciências naturais.

Assim, notamos que ambos os programas aqui analisados promovem a pesquisa em ensino de ciências coerente com linhas teóricas atuais e com diversidade metodológicas, buscando relação com o "chão" da escola. Como possibilidades de trabalhos futuros esse estudo aponta para a necessidade de aprofundamento das compreensões sobre a relação entre o corpo docente do programa e a formação ofertada aos mestrandos.

\section{REFERÊNCIAS}

AIKENHEAD, G. The social contract of science. In: SOLOMON, J.: AIKENHEAD, G. (Eds.). STS Education. New York: Teachers College Press, 1994, p. 11-21.

CACHAPUZ, A.; GIL-PÉREZ, D.; CARVALHO, A. M. P.; PRAIA, J.; VILCHES, A. A necessária renovação do ensino das ciências. $3^{a}$ ed. São Paulo: Editora Cortez, 2011.

CAMARGO, B. V.; JUSTO, A. M. IRAMUTEQ: um software gratuito para análise de dados textuais. Temas em Psicologia, Ribeirão Preto, v. 21, n. 2, p. 513-518, dez. 2013. Disponível em <http://pepsic.bvsalud.org/scielo.php?script=sci_arttext\&pid=S1413389X2013000200016\&lng=pt\&nrm=iso>. acessos em 16 abr. 2021. http://dx.doi.org/10.9788/TP2013.2-16. 
CAPES. Documento de área 2019 - Ensino. Brasília, 2019. Disponível em: Disponível em: https://www.gov.br/capes/pt-br/centrais-de-conteudo/ENSINO.pdf. Acesso em: 23 març. 2021.

FERREIRA, M.; MÜNCHEN, S. A contextualização no ensino de ciências: reflexões a partir da Educação do Campo. Revista Insignare Scientia, v. 3, n. 4, p. 380-399, 20 nov. 2020.

GENOVESE, L. G. R., MORAES, A. G., BOZELI, F. C., GEHLEN, S. T., MIQUELIN, A. F. e SASSERON, L. H. Apresentação. IN: GENOVESE, L. G. R. et al. (Eds.). Diálogo entre as múltiplas perspectivas na pesquisa em Ensino de Física. São Paulo: Editora Livraria da Física, 2016, p. 9-22.

PÉREZ, Z. P. Los diseños de método mixto en la investigación en educación: Una experiencia concreta. Revista Electrónica Educare, v. 15, n. 1, p. 15-29, 2011. Disponível em: http://www.revistas.una.ac.cr/index.php/EDUCARE/article/view/867.

POSENSINO. 2021. Área de Concentração e Linhas de Pesquisa. Disponível em: <http://propeg.uern.br/posensino/default.asp?item=posensino-area-concentracao >. Acesso em: 04 de fev. de 2021.

PPGE. 2021. Linhas de Pesquisa. Disponível em: < http://propeg.uern.br/ppge/default.asp?item=ppge-linhas-de-pesquisa > . Acesso em: 04 de fev. de 2021.

RAMOS, M. G.; LIMA, V. M. do R.; AMARAL-ROSA, M. P. Contribuições do software IRAMUTEQ para a Análise Textual Discursiva. 1., 2018. Congresso IberoAmericano em Investigação Qualitativa. Anais [...]. Fortaleza: CIAIQ, 2018. vol. 1, p. $505-514$.

RATINAUD, P. IRAMUTEQ: Interface de $\mathbf{R}$ pour les Analyses

Multidimensionnelles de Textes et de Questionnaires [Computer software]. 2009.

Disponível em: http://www.iramuteq.org. Acesso em: 18 out. 2020.

SILVA, M. G.; AMARAL, E. M. R. Pesquisa em ensino de biologia: características da produção acadêmica do Programa de Pós-Graduação em Ensino de Ciências da Universidade Federal Rural de Pernambuco, Brasil. Ciência \& Educação. v. 21, n. 2, p. 285-305, 2015.

SOUSA, R.; SILVA, F. Elaborando uma análise ator-rede sobre o Role Playing Game “energizando". Revista Insignare Scientia, v. 4, n. 3, p. 194-210, 3 mar. 2021.

SOUZA, F. das C. S.; NUNES, A. O.; OLIVEIRA, M. A.. O Programa De PósGraduação Em Educação Profissional e Tecnológica e a formação humana integral: análise da produção acadêmica no IFRN/Mossoró. Revista Brasileira da Educação Profissional e Tecnológica, v. 2, n. 19, p. e11629, dez. 2020. ISSN 2447-1801. Disponível em: <http://www2.ifrn.edu.br/ojs/index.php/RBEPT/article/view/11629>. Acesso em: 16 abr. 2021. doi: https://doi.org/10.15628/rbept.2020.11629.

Recebido em: 30/05/2021

Aceite em: 13/08/2021 
SOUZA, M.A. R.; WALL, M.L.; THULER, A.C.M.C.; LOWEN, I.M.V.; PERES, A.M. The use of IRAMUTEQ software for data analysis in qualitative research. Revista da Escola de Enfermagem da USP. v. 52, e03353, 2018. DOI:

http://dx.doi.org/10.1590/S1980-220X2017015003353.

TEIXEIRA, P. M. M. Pesquisa em Ensino de Biologia no Brasil (1972-2004): um estudo baseado em dissertações e teses. 2008. 417f. Tese (Doutorado em Educação) Faculdade de Educação, Universidade Estadual de Campinas, Campinas, 2008.

YAGER, R. E. History of Science/Technology/Society as reform in the United States. In: YAGER, R. E. (Ed.). History of Science/Technology/Society as reform in Science Education. New York: State University of New York Press, 1996, p. 3-16.

Recebido em: 30/05/2021

Aceite em: 13/08/2021 